\title{
ParecerEdu: um Aplicativo para Apoio à Elaboração de Pareceres nos Anos Iniciais de Ensino Fundamental
}

\author{
Igor A. Oliveira, Amanda Meincke Melo
}

\author{
Universidade Federal do Pampa (Unipampa) - Campus Alegrete \\ Av. Tiarajú, 810 - Ibirapuitã - 97.546-550 - Alegrete - RS - Brasil \\ igornnt@gmail.com, amanda.melo@unipampa.edu.br
}

\begin{abstract}
Digital technologies are used pervasively, including at school, also supporting management activities. In a literature review related to school management in elementary school and in an analysis of competitors of mobile applications, no solutions were found specifically aimed at the preparation of students' descriptive evaluation. This article presents the process of developing a mobile application that, integrating Human-computer Interaction to Software Engineering, directly involved teachers in the conception, design and validation of a mobile application to support the preparation of individual descriptive evaluation. As a result, there is the ParecerEdu application that is in use and under observation.
\end{abstract}

Resumo. Tecnologias digitais são utilizadas pervasivamente, inclusive no contexto escolar, apoiando também atividades de gestão. Em uma revisão de literatura relacionada à gestão escolar no ensino fundamental e em uma análise de concorrentes de aplicativos móveis, não foram encontradas soluções voltadas especificamente à elaboração de pareceres descritivos de estudantes. Este artigo apresenta o processo de desenvolvimento de um aplicativo móvel que, integrando a Interação Humano-computador à Engenharia de Software, envolveu diretamente professores na concepção, no projeto e na validação de um aplicativo móvel para apoiar a elaboração de pareceres descritivos. Como resultado, tem-se o aplicativo ParecerEdu que está em uso e em observação.

\section{Introdução}

Nossa sociedade faz uso pervasivo de tecnologias digitais, em diversos setores, para apoiar e aperfeiçoar suas atividades. Na Educação, as tecnologias digitais estão presentes em seus diferentes níveis e modalidades, contribuindo não somente em atividades de ensino e aprendizagem, mas também de comunicação, de formação em serviço e de gestão, entre outras.

Um software de gestão, em particular, auxilia a instituição educacional a desenvolver suas atividades de forma mais produtiva e/ou a obter dados para a tomada de decisões [Nagar, Rahoo e Rehman 2018]. Para contribuir com as atividades de gestão escolar, em contato com professoras e professores de duas escolas estaduais de Alegrete/RS, identificou-se a demanda por uma solução que auxilie no acompanhamento de seus estudantes e apoie a elaboração de pareceres descrtivos.

Em uma revisão de literatura relacionada à gestão escolar no ensino fundamental, identificaram-se sistemas de software para apoio à gestão, incluindo software de propósito geral e software especializados. Entre os trabalhos relacionados, não há relato do processo de Engenharia de Software envolvido nem como ocorreu a participação dos usuários. Além 
disso, nenhuma das soluções apresentadas é voltada especificamente à elaboração de pareceres descritivos pelos professores, a partir de dados de acompanhamento dos estudantes em sala de aula. Ademais, em uma pesquisa por aplicativos móveis concorrentes, também não foram identificadas soluções especializadas para essa tarefa.

Para apoiar professores dos anos iniciais do ensino fundamental e gestores escolares na elaboração de pareceres descritivos, desenvolveu-se um aplicativo móvel, denominado ParecerEdu. Para isso, estabeleceu-se um processo colaborativo de Engenharia de Software, com a participação de professores e professoras da educação básica, apoiado por técnicas de Interação Humano-computador. Este artigo apresenta o processo de desenvolvimento desse aplicativo e alguns de seus artefatos, estando estruturado como segue. Na Seção 2, é apresentada a revisão de literatura, realizando-se uma síntese dos trabalhos relacionados. $\mathrm{Na}$ Seção 3, são sumarizados a abordagem de pesquisa adotada, o referencial teóricometodológico, assim como materiais e métodos utilizados. Na Seção 4, são apresentados resultados e discussões. Finalmente, na Seção 5, são realizadas as considerações finais deste trabalho.

\section{Revisão de Literatura}

A fim de investigar problemas de gestão escolar no ensino fundamental abordados com soluções em software e tecnologias para apoio à gestão no ensino fundamental, realizaramse pesquisas nas bases ACM Digital Library (https://dl.acm.org/), IEEE Xplore (https://ieeexplore.ieee.org/), Scopus (https://www.scopus.com/) e portal de publicações da Comissão Especial de Informática na Educação (CEIE) (https://www.br-ie.org/pub/). Adotou-se a string de busca software AND "elementary school" AND management nas bases ACM Digital Library, IEEE Xplore e Scopus e a string escola AND gestão no portal de publicações da CEIE. À exceção da pesquisa no portal de publicação da CEIE, as demais contemplaram o período [abr. 2014, abr. 2019]. Ao todo, identificaram-se 45 trabalhos, dentre os quais os sumarizados, a seguir, relacionam-se ao escopo desta pesquisa.

Nagar, Rahoo e Rehman (2018) reportam resultados de uma pesquisa sobre a adoção de software no apoio à gestão escolar. Entre as ferramentas mais utilizadas nas escolas investigadas, estão o Microsoft Word para apoio a atividades de escritório e o Microsoft Excel para atividades de contabilidade. Segundo os autores, o alto custo de software de gestão e a baixa confiabilidade dos software de baixo custo são os principais problemas enfrentados na adesão de um sistema de gestão escolar.

Pujadi, Fathurrozi e Theresia (2016) propõem um sistema de apoio a gestores na contratação e na alocação de professores em escolas públicas do governo da Indonésia. Esse sistema adota um modelo multicrietérios, recomendando os profissionais mais próximos das necessidades estratégicas de cada escola. Assim, o sistema propõe maior assertividade nas tarefas de contratação e de alocação de professores.

Alcantara, Nascimento e Oliveira (2016) apresentam a ferramenta ConectEdu, desenvolvida em plataforma web para o gerenciamento de instituições de ensino, que busca promover a integração da escola com as famílias. Pais e estudantes têm acesso a eventos escolares, banners de campanha e aulas, assim como a jogos educacionais, espaço para reportar bullying, notas e frequência. Professores recebem notícias da escola, têm acesso à agenda escolar, programas para atividades diárias, provas, testes e trabalhos. Além disso, podem informar a frequência dos estudantes. Há, ainda, um painel de gerenciamento geral da escola. Este apresenta a quantidade de alunos da escola, é responsável por mensagens 
aos usuários, resumos, gráficos, além de informar índices das turmas como: frequência, vagas disponíveis e rendimento.

Camilotti (2014) apresenta o uso de blogs como ferramenta de gestão contextualizada e colaborativa. Em um blog central, eram indexados blogs das escolas, sendo possível realizar o acompanhamento das unidades escolares. Além de apoiar na comunicação, os blogs serviam à orientação, à cooperação e à divulgação de práticas.

Oliveira, Freitas e Tono (2008) analisam um sistema de gestão escolar de instituições públicas, denominada SERE, que permite a manutenção de dados de planejamento escolar, registro escolar e estrutura de funcionamento. Com base nos dados dos estudantes, o sistema gera uma série de relatórios, como requerimento de matrícula, declaração de matrícula, boletim e histórico escolar. Os autores refletem sobre a utilização dos dados na gestão pedagógica e as dificuldades na alimentação desses dados, que podem influenciar no uso de um sistema de gestão.

Os trabalhos identificados apresentaram o uso de tecnologias digitais no apoio à gestão escolar. Contudo, nenhum especifica seu processo de Engenharia de Software nem como ocorreu a participação dos usuários em sua concepção. Ademais, nenhuma dessas soluções é voltada especificamente à elaboração de pareceres descritivos pelos professores, a partir de dados de acompanhamento dos estudantes no dia a dia da sala de aula.

\section{Metodologia}

Para realizar este trabalho, adotou-se uma abordagem qualitativa de pesquisa, pela realização de um estudo exploratório [Triviños 2011], com o intuito de investigar o domínio educacional e construir conhecimentos sobre esse domínio. Entre esses conhecimentos, estão os problemas enfrentados por professores e gestores escolares, assim como possíveis soluções para esses problemas.

O referencial teórico-metodológico está fundamentado, principalmente, na Semiótica Organizacional [Baranauskas 2013] e na integração da Interação Humanocomputador à Engenharia de Software [Barbosa e Silva 2010], com auxílio de técnicas do Design Participatipativo [Muller, Haslwanter e Dayton 1997]. Enquanto a Semiótica Organizacional foi adotada para auxiliar na elaboração do problema e elicitação de requisitos, a Engenharia de Software, apoiada por conceitos e métodos da Interação Humano-computador, contribuiu ao desenvolvimento da solução em software.

As principais etapas envolvidas neste trabalho são: elaboração do problema, elicitação e especificação de requisitos, desenvolvimento da solução.

\subsection{Elaboração do problema}

A partir do problema focal "Tecnologias Digitais para a Gestão Escolar", no mês de abril de 2019, levantaram-se os principais problemas enfrentados, no ensino fundamental, em duas escolas de educação básica, situadas no município de Alegrete/RS: Escola Estadual de Ensino Fundamental (EEEF) Arthur Hormain e a EEEF Oswaldo Dornelles.

Um questionário foi elaborado, com perguntas fechadas e abertas, para ajudar a compreender o uso de tecnologias digitais por professores e gestores dessas escolas, assim como os problemas enfrentados em suas rotinas profissionais. Responderam ao questionário dezoito professores e duas orientadoras educacionais. 
Em ambas as escolas, logo após a aplicação dos questionários, realizaram-se sessões de tempestade de ideais, com o apoio de um Quadro de Avaliação - artefato da Semiótica Organizacional (Tabela 1), buscando-se identificar questões, problemas, ideias e soluções relacionados às atividades desenvolvidas pelos professores e professoras na escola, na sala de aula e em casa.

Tabela 1. Quadro de Avaliação, adaptado de Baranauskas (2013)

\begin{tabular}{|l|l|l|}
\hline & Questões / Problemas & Ideias / Soluções \\
\hline Na escola & & \\
\hline Na sala de aula & & \\
\hline Em casa & & \\
\hline
\end{tabular}

\subsection{Elicitação e especificação dos requisitos}

Inicialmente, adotou-se a Cebola Semiótica (Figura 1) - artefato da Semiótica Organizacional - para auxiliar no registro e na análise de partes interessadas no problema focal. No centro do artefato, foi identificado o problema focal "Apoio à elaboração de pareceres nos anos iniciais do ensino fundamental", delimitado a partir dos resultados das sessões de tempestade de ideias. Nas camadas subsequentes foram mapeadas as pessoas e as instituições que colaboram na solução do problema focal e/ou que de alguma maneira são impactadas por ele. Além de analisar os papeis, realizou-se a análise de concorrentes, que consistiu na exploração, com apoio da string escola parcer, de forma assistemática, das duas principais lojas de aplicativos: Apple Store e Play Store.

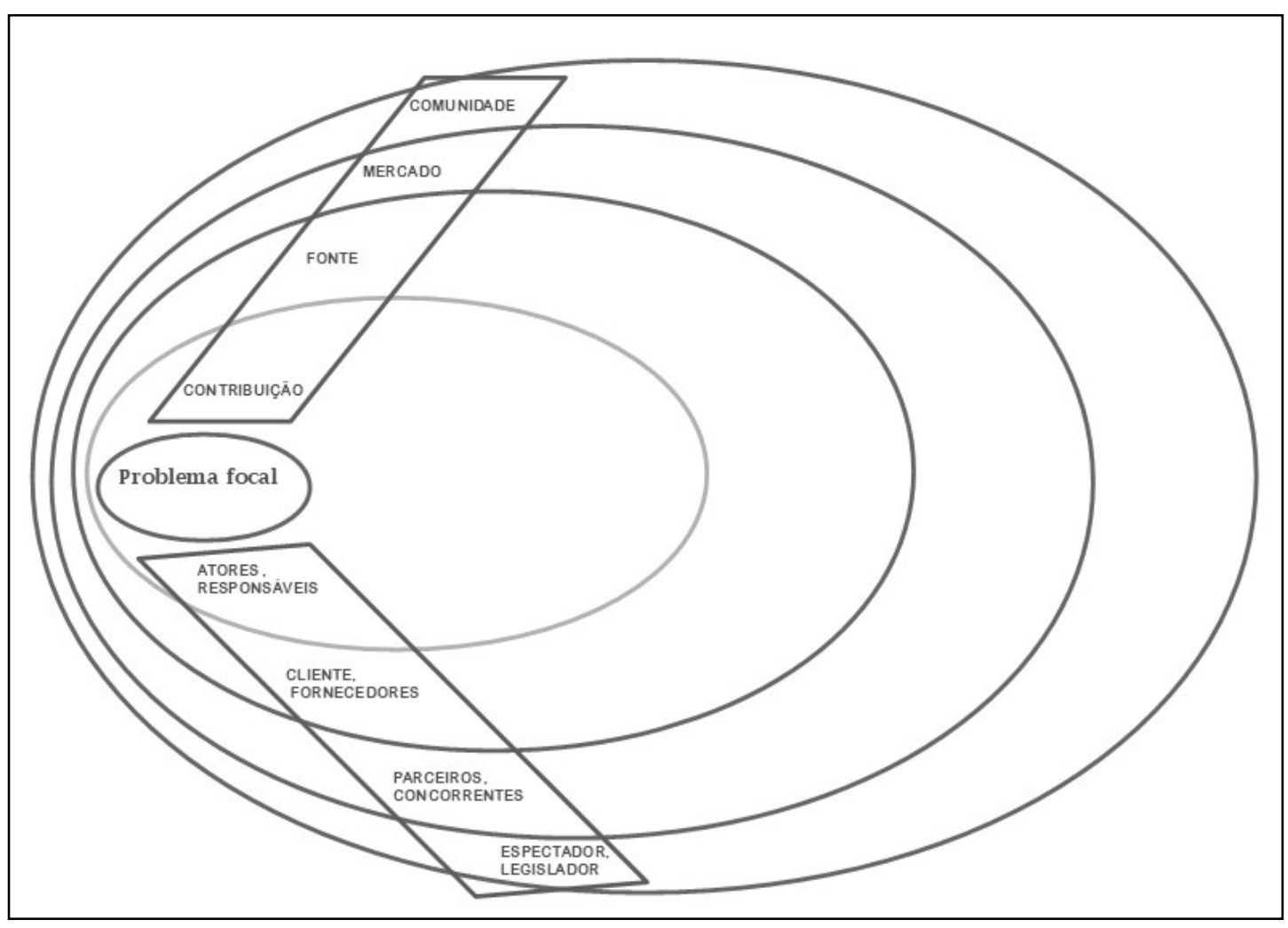

Figura 1. Cebola Semiótica, adaptada de Baranauskas (2013) 
As informações organizadas na Cebola Semiótica foram validadas pela supervisora educacional da escola EEEF Oswaldo Dornelles, que também integra o quadro de professores da EEEF Arthur Hormain.

Para compreender o fluxo envolvido na elaboração de um parecer e sua organização, foi realizada uma entrevista com a supervisora educacional da EEEF Oswaldo Dornelles, considerando-se seu papel no processo de revisão e de publicização dos pareceres, e uma análise documental [Sommerville 2011], que envolveu a consulta de pareceres registrados na escola. Considerando-se aspectos éticos, para essa análise, foram ocultados nomes de alunos e professores dos pareceres consultados. Então, para modelar o processo de elaboração de um parecer na escola, adotou-se a notação BPMN (do inglês, Business Process Model and Notation) [White 2004].

Como parte da Engenharia de Requisitos, para analisar e especificar requisitos, utilizou-se um Diagrama de Casos de Uso da notação UML (do inglês, Unified Modeling Language) [Sommerville 2011]. Em seguida, foram adotadas Histórias de Usuário para especificá-los [Cohn 2004]. Procurava-se, assim, com os Casos de Uso, entender a interação entre o usuário e o sistema proposto e, com as Histórias de Usuário, comunicar os requisitos aos participantes sem considerar, ainda, aspectos tecnológicos. Esses requisitos também foram validados com a supervisora educacional da EEEF Oswaldo Dornelles.

Uma oficina de prototipação [Muller, Haslwanter e Dayton 1997] foi, então, realizada na EEEF Oswaldo Dornelles, na qual participaram a supervisora educacional e uma professora dos anos iniciais do ensino fundamental, com especialização em Informática na Educação. As participantes foram orientadas a desenhar, com êfase na estrutura e conteúdos, suas visões para a interface, de acordo com suas necessidades, considerando o problema focal em perspectiva, "Apoio à elaboração de pareceres nos anos iniciais do ensino fundamental". Para isso, foram utilizadas as Histórias de Usuário, folhas de papel branco, lápis de escrever e caneta preta ou azul.

\subsection{Desenvolvimento da solução}

Para o desenvolvimento da solução, adotou-se uma abordagem iterativa, conforme ilustrado na Figura 2.

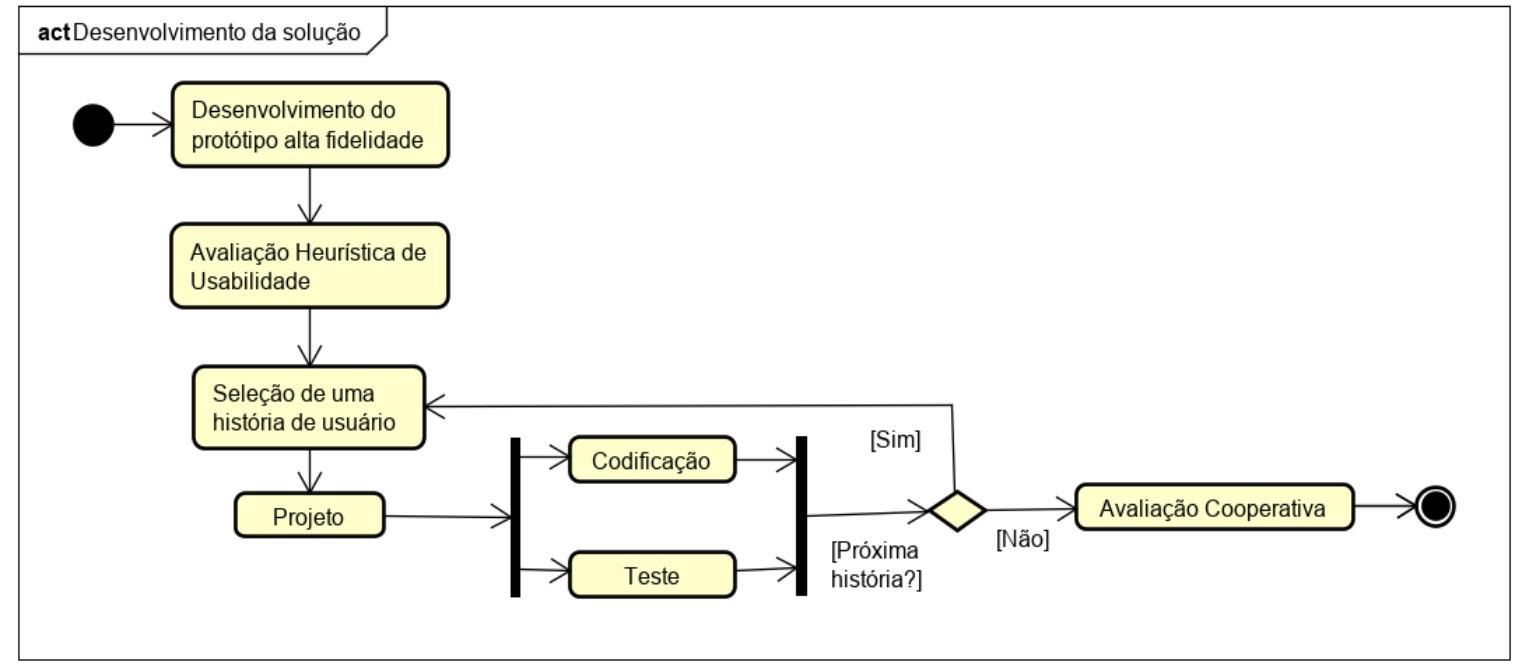

Figura 2. Diagrama de atividades do desenvolvimento da solução 
A partir do protótipo desenhado com a colaboração de usuários finais, desenvolveuse um protótipo de alta fidelidade [Barbosa e Silva 2010]. Este foi, então, avaliado quanto a sua usabilidade com apoio do protocolo de Avaliação Heurística de Usabilidade [Nielsen 1994], com a colaboração de oito estudantes da área da Computação, que já haviam concluído o componente curricular obrigatório Interação Humano-computador, ofertado no Campus Alegrete da Unipampa.

De forma iterativa, o aplicativo móvel passou a ser construído. A cada iteração, histórias de usuário eram selecionadas e incorporadas ao projeto do software, codificadas e testadas. Adotou-se uma arquitetura em camadas, com apoio do Framework Flutter (https://flutter.dev/), utilizado no desenvolvimento de aplicativos móveis para Android e iOS.

Para avaliar e validar a solução, em novembro de 2019, realizaram-se sessões de Avaliação Cooperativa [Muller, Haslwanter e Dayton 1997]. Essas sessões contaram com a colaboração de duas professoras das escolas envolvidas, que também participaram da concepção do software, sendo que uma delas colaborou diretamente em seu projeto de interface. Individualmente, elas receberam seis tarefas para serem realizadas com auxílio do aplicativo: registre um grupo (turma) de 5 alunos, defina dois critérios de avaliação para linguagens, realize a avalição dos alunos segundo os critérios definidos, visualize o gráfico de desempenho individual de um aluno, visualize o gráfico de desempenho de uma turma e realize uma observação sobre um aluno.

Ao final do processo e com melhorias realizadas, o aplicativo foi gerado para a plataforma Android e quatro professoras foram instruídas para que pudessem instalar e fazer o uso da ferramenta em suas rotinas de sala de aula. Esse uso está em observação no contexto do GEInfoEdu - Grupo de Estudos em Informática na Educação, programa de extensão e grupo de pesquisa do Campus Alegrete da Unipampa.

\section{Resultados e Discussões}

Mais da metade dos que responderam ao questionário, treze de vinte participantes, utilizam smartphones em suas rotinas profissionais. Esse uso envolve a realização de pesquisas, uso de aplicativos, acesso a sugestões de atividades e trabalhos para desenvolver com os estudantes. Entre os recursos mais utilizados com propósitos educacionais por esses respondentes, ao lado dos smartphones, estão laboratório de informática, canhão de projeções e notebook.

As Tabelas 2 e 3, a seguir, registram as questões, os problemas, as ideiais e as soluções identificados com os professores nas escolas partícipes. Em ambas as escolas, pôde-se perceber a menção ao apoio à elaboração de pareceres, incluindo a adoção de gráficos e o acompanhamento individual de estudantes.

Tabela 2. Transcrição do Quadro de Avaliação preenchido na EEEF Arthur Hormain

\begin{tabular}{|l|l|l|}
\hline & \multicolumn{1}{|c|}{ Questões / Problemas } & \multicolumn{1}{c|}{ Ideias / Soluções } \\
\hline Na escola & planejamento trimestral & planejamento seminal \\
\hline Na sala de aula & tempo, desnível intelectual & $\begin{array}{l}\text { desenvolvimento de atividades diversificadas, } \\
\text { diferentes metodologias, slides, registro de aula }\end{array}$ \\
\hline Em casa & plano de ensino, plano de aula & modelo unificado, gráfico parecer \\
\hline
\end{tabular}


Tabela 3. Transcrição do Quadro de Avaliação preenchido na EEEF Oswaldo Dornelles.

\begin{tabular}{|c|c|c|}
\hline & Questões / Problemas & Ideias / Soluções \\
\hline Na escola & $\begin{array}{l}\text { registro de chamada com um } \\
\text { diário de classe, elaboração do } \\
\text { parecer }\end{array}$ & $\begin{array}{l}\text { Software para digitar em sala a chamada e o } \\
\text { registro do diário de classe e que isso fique } \\
\text { centralizado, acompanhamento do aluno para as } \\
\text { habilidades necessárias de acordo com o seu nível, } \\
\text { de forma individual }\end{array}$ \\
\hline Na sala de aula & $\begin{array}{l}\text { problema no entendimento da } \\
\text { grafia dos alunos, tempo, } \\
\text { materiais para a sala de aula }\end{array}$ & $\begin{array}{l}\text { um software gerenciador de tempo do professor, } \\
\text { um aplicativo para pauta nas reuniões, um } \\
\text { aplicativo para alimentar conteúdos que podem ser } \\
\text { utilizados em sala de aula }\end{array}$ \\
\hline Em casa & $\begin{array}{l}\text { levar para casa o trabalho da } \\
\text { escola e problemas do dia a dia } \\
\text { escolar }\end{array}$ & robô doméstico e dotado de inteligência \\
\hline
\end{tabular}

A partir dos resultados das sessões de tempestade de ideias e das conversas estabelecidas em ambas as escolas, definiu-se como problema focal o "Apoio à elaboração de pareceres nos anos iniciais do ensino fundamental". Tendo como referência esse problema focal, ao ser realizada a análise de partes interessadas, em particular ao se procurar por aplicativos nas lojas Apple Store e Play Store, não foram identificadas soluções que atendessem a essa demanda. Decidiu-se, assim, pelo desenvolvimento de um aplicativo móvel para atendê-la. A Tabela 4, a seguir, registra as Histórias de Usuário especificadas para o aplicativo.

Tabela 4. Histórias de Usuário especificadas para o aplicativo móvel ParecerEdu

\begin{tabular}{|c|c|}
\hline Codigo & Descrição \\
\hline HU01 & Como professor gostaria de cadastrar as escolas em que eu trabalho \\
\hline HU02 & Como professor gostaria de cadastrar minhas turmas \\
\hline HU03 & Como professor gostaria de cadastrar os alunos da turma em que eu trabalho \\
\hline HU04 & Como professor gostaria de criar critérios de aprendizagem para cada área de conhecimento \\
\hline HU05 & $\begin{array}{l}\text { Como professor gostaria de escrever minhas observações sobre cada aluno e em qualquer } \\
\text { momento }\end{array}$ \\
\hline HU06 & $\begin{array}{l}\text { Como professor gostaria de poder avaliar o aluno decorrente aos critérios de aprendizagem em } \\
\text { que eu cadastrei anteriormente }\end{array}$ \\
\hline HU07 & Como professor gostaria de poder visualizar o estado atual da turma por meio de um gráfico \\
\hline HU08 & $\begin{array}{l}\text { Como professor gostaria de poder visualizar o estado atual de um aluno por meio de um } \\
\text { gráfico }\end{array}$ \\
\hline
\end{tabular}

A Figura 3, a seguir, apresenta protótipos de baixa fidelidade desenvolvidos por uma professora do ensino fundamental e a supervisora da EEEF Oswaldo Dornelles. A partir da análise desses protótipos, procurando-se identificar padrões, a forma de apresentar os elementos de interface e os dados, foi desenvolvido o protótipo de alta fidelidade, apresentado na Figura 4. 


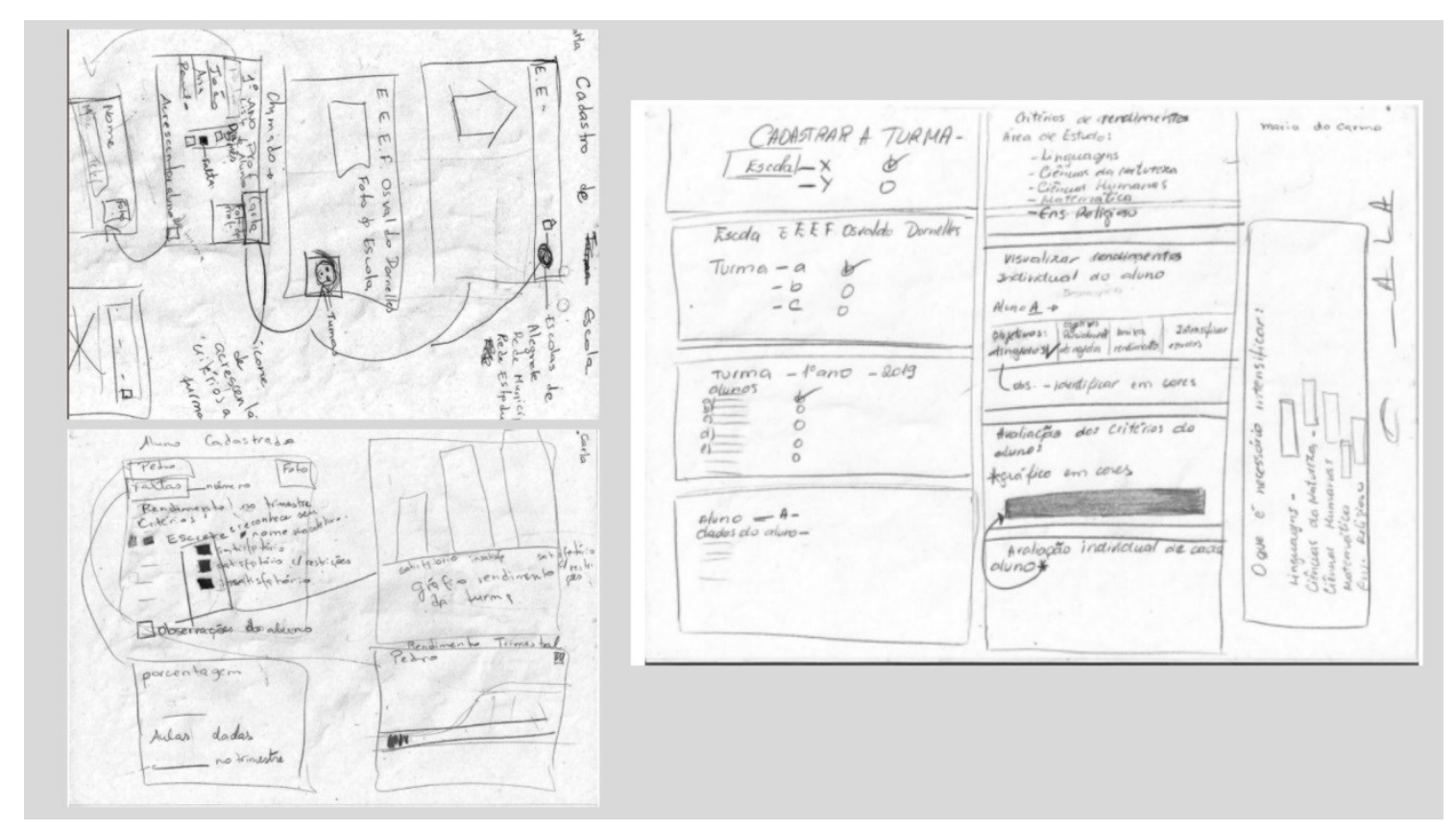

Figura 3. Protótipo de baixa fidelidade
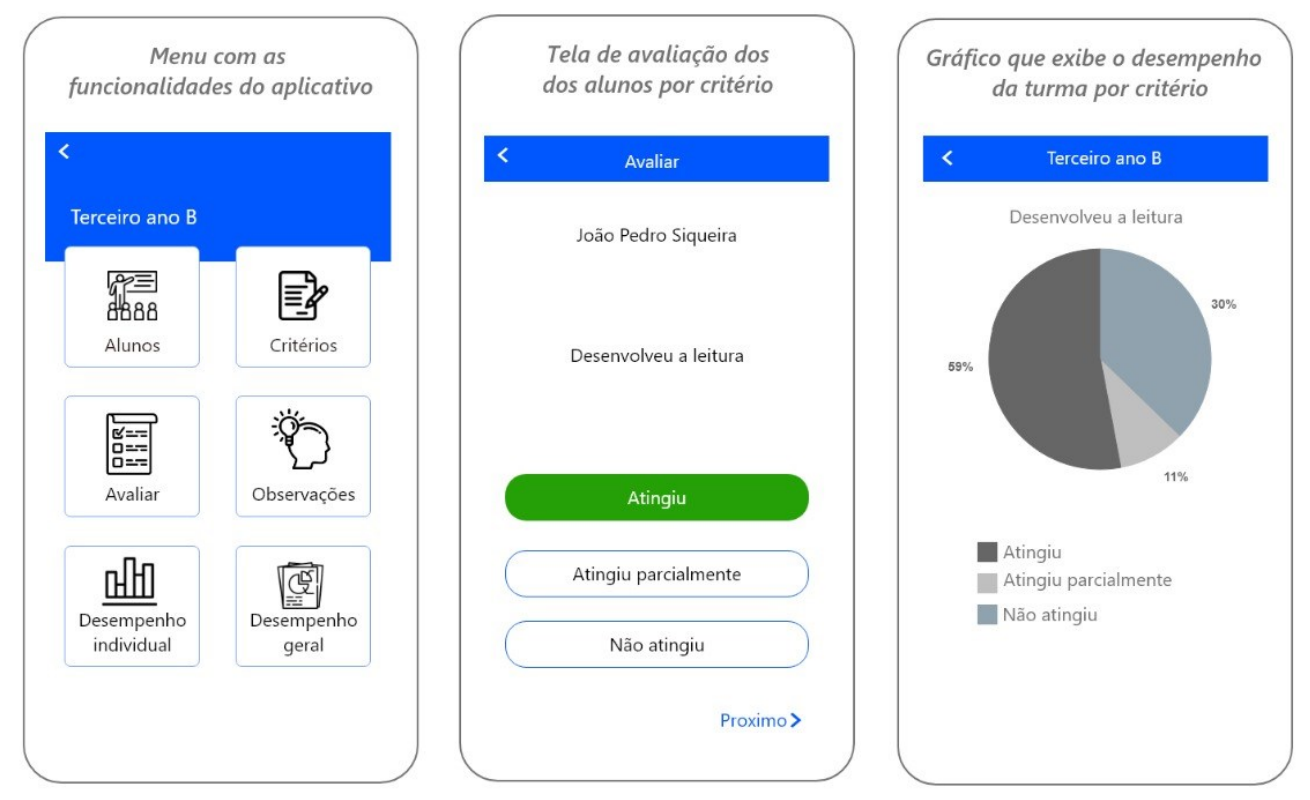

Figura 4. Exemplos de telas do protótipo de alta fidelidade

Em sequência, da esquerda para a direita, tem-se: a tela do menu principal, que apresenta a principais funcionalidades relacionadas à gestão de uma turma (ex.: gestão de alunos, gestão de critérios, avaliação, observações, acesso ao desempenho individual e ao desempenho geral); a tela de avaliação, onde o professor pode avaliar um estudante a partir dos os critérios definidos por ele; e, finalmente, a página de desempenho geral, que apresenta o gráfico de desempenho de uma turma.

Entre os problemas de alta severidade, identificados a partir da Avaliação Heurística de Usabilidade do protótipo de alta fidelidade, destacam-se: a impossibilidade de perceber 
em qual interface o usuário se encontra, a ausência de confirmação ao realizar uma operação e até mesmo problemas estéticos, como o uso de cores em gráficos. Esses problemas foram considerados no desenvolvimento da versão final do aplicativo (Figura 5).

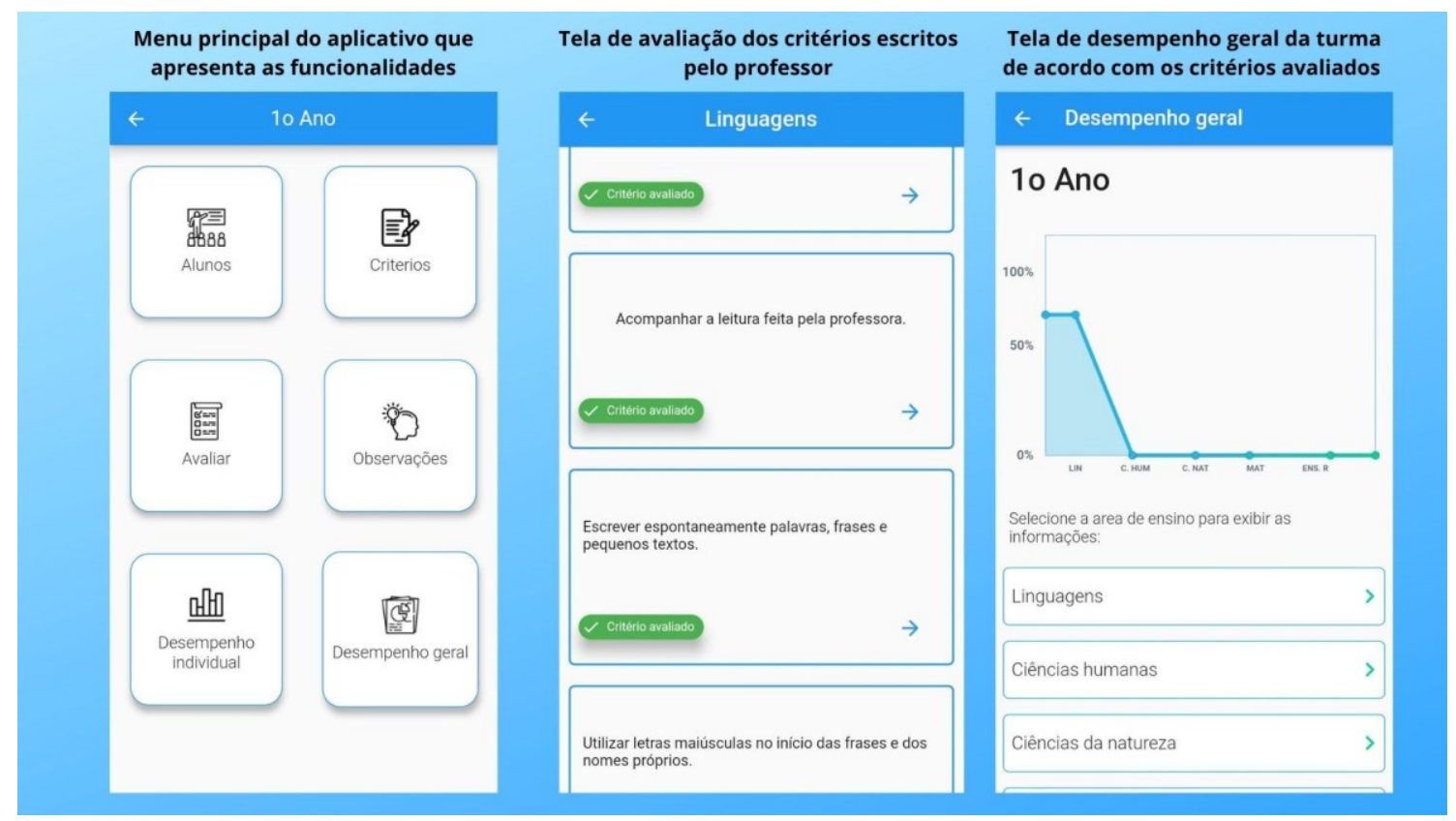

Figura 5. Exemplos de telas do aplicativo em sua versão final

Através da Avaliação Cooperativa, pode-se perceber que a usuária envolvida diretamente em seu projeto de interface de usuário apresentou maior facilidade no uso do aplicativo do que a usuária que participou apenas das atividades de sua concepção. Ambas, contudo, apresentaram uma boa aceitação para a solução apresentada. A possiblidade de avaliar, diariamente, as emoções dos estudantes foi indicada por uma das professoras como um requisito para próximas versões do aplicativo, pois estas afetam diretamente a aprendizagem.

\section{Considerações Finais}

Propôs-se, com este trabalho, contribuir, de modo efetivo, à gestão escolar. Para isso, em um processo que integra a Interação Humano-computador à Engenharia de Software, envolveram-se professores do ensino fundamental no desenvolvimento de um aplicativo, denominado ParecerEdu, desde sua concepção, passando pelo projeto da interface de usuário e sua validação.

Com esse aplicativo, a partir das avaliações e anotações realizadas no cotidiano escolar sobre seus alunos e informações apresentadas graficamente, os professores podem elaborar pareceres descritivos, a partir de uma visão individualizada e de turma. Além disso, podem refletir sobre sua prática e rever estratégias de ensino e de avaliação.

A solução entregue está bastante próxima daquilo que foi idealizado e o aplicativo está em uso por quatro professoras das escolas participantes. Este uso está em observação no contexto do GEInfoEdu - Grupo de Estudos em Informática na Educação, buscando a evolução da solução a partir da experiência de uso para, então, difundi-lo amplamente. 


\section{Agradecimentos}

Às professoras e aos professores da EEEF Arthur Hormain e EEEF Oswaldo Dornelles. À equipe do GEInfoEdu - Grupo de Estudos em Informática na Educação, programa de extensão e grupo de pesquisa do Campus Alegrete da Unipampa. À equipe do projeto de ensino GEIHC - Grupo de Estudos em Interação Humano-computador, do Campus Alegrete da Unipampa. Ao Programa de Desenvolvimento Acadêmico (PDA 2019) da Unipampa.

\section{Referências}

Alcantara, R.; Nascimento, A.; Oliveira, L. (2016) "Ferramenta de Gestão Pedagógica". In Anais dos Workshops do V CBIE, p. 145-150. SBC.

Baranauskas, M. C. C. (2013) “O Modelo Semio-Participativo de Design”, In: Codesign de Redes Digitais: Tecnologia e Educação a Serviço da Inclusão Social, organizado por Baranauskas, M. C. C.; Martins, M. C.; Valente, J. A., Penso Editora, Porto Alegre.

Barbosa, S.; Silva, B. (2010), Interação Humano-computador, Elsevier Brasil, 1. ed.

Cohn, M. (2004), User Stories Applied: For Agile Software Development, AddisonWesley.

Camilotti, D. (2014) “O Blog como Ferramenta de Apoio às Funções do NTERegional: Gestão, Acompanhamento e Orientação do Uso das TDIC na Escola". In: $X X$ WIE, p. 318-327. SBC.

Gaspar, I; Seabra, F; Neves, C. (2012). A supervisão pedagógica: significados e operacionalização. In Revista Portuguesa de Investigação Educacional, v. 12, p. 29-57.

Muller, M. J.; Haslwanter, J. H.; Dayton, T. (1997) "Participatory Practices in the Software Lifecycle", In: Handbook of Human-Computer Interaction, 2. ed., Editado por Helander, M. G.; Landauer, T. K.; Prabhu, P. V., Elsevier, Amsterdan.

Nagar, M. A. K.; Rahoo, L. A.; Rehman, H. A. et al. (2018) "Education Management Information Systems in the Primary Schools of Sindh a case study of Hyderabad Division". In: V ICETAS. IEEE.

Nielsen, J. (1994) How to Conduct a Heuristic Evaluation, https://www.nngroup.com/articles/how-to-conduct-a-heuristic-evaluation, Julho 2020.

Oliveira, S.; Freitas, M.; Tono, C. (2008) "Gestão da Informação na Escola Pública Estadual do Paraná: Aplicabilidade Pedagógica do Sistema de Informação do Registro Escolar". In: XIX SBIE, SBC.

Pujadi, T.; Fathurrozi, A.; Theresia, S. (2016) "Using Analytical Hierarchy Process for the decision support system in teacher placement". In: ICIMTech 2016. IEEE.

Barbosa, S.; Silva, B. (2010), Interação Humano-computador, Elsevier Brasil, 1. ed.

Sommerville, I. (2011), Engenharia de Software, Pearson Brasil.

Triviños, A. N. S. (2011), Introdução à pesquisa em ciências sociais: a pesquisa qualitativa em educação, Atlas.

White, S. A. (2004), Introduction to BPMN. IBM Cooperation, v. 2. 